adaptability, but the relationship is not lucidly or adequately established. Chapter 3 provides morphological descriptions of some economically important species and of the families Argasidae and Ixodidae (omitting Nuttalliellidae). Chapter 4, a good review of the capitulum and feeding mechanism, is followed by an incomplete account of direct effects of tick bites. Feeding habits, anatomy and physiology of the alimentary canal, excretion and osmotic control, circulatory system, and respiratory system are lumped in Chapter 5, and reproduction, development, and life-histories in Chapter 6. Regulating mechanisms of unfed ticks comprise Chapter 7. The coverage of host preferences and behaviour of feeding and fed ticks, Chapter 8, as well as that of life-histories, reveals a remarkable lack of intimacy with these subjects.

The next three chapters deal with spirochæta, bacilli and paralysis (sic) transmitted by ticks (10), and protozoa (11), rickettsiae (12), and viruses (13) transmitted by ticks. The grouping of paralysis with the organisms transmitted by ticks is unfortunate. These chapters, and Chapter 14 on control, are weak. For example, the fascinating story of the Russian spring-summer group of viruses, well documented in a vast body of literature including much in the English language, is all but overlooked. Japanese $B$, and American, European and Russian encephalitis-causing viruses are not even differentiated and it is difficult to determine whether their important vectors are mosquitoes or ticks. Long lists of scientific names of vertebrate hosts are quite useless for students. The extensive information on Ornithodoros erraticus and relapsing fever is scarcely mentioned. The numerous important epidemiological factors in dissemination of $Q$ fever apart from tick agencies are noted only in passing, in the last sentence on the subject. On p. 303, we read, "The microorganisms of Pasteurella tularensis are the ætiological agents of tularaemia". Ornithodoros moubata is said to occur in Egypt (p. 297) (an ancient incorrect literature statement long and widely disproved) and spirochæta recovered from $O$. erraticus in Egypt are discussed in the same paragraph with distribution and feeding habits of $O$. moubata in tropical Africa. Scientific names are carelessly handled: $A$. minanensis (p. 298) is a name dropped generations ago; frequently one species is referred to by two different names on one page. Such confusion, errors and omissions reduce the value of this book as a text or reference. HaRRY HoogstraAl

\section{MEDUSA OF THE WORLD}

\section{Synopsis of the Medusæ of the World}

By P. L. Kramp. (Journal of the Marine Biological Association of the United Kingdom, Vol. 40.) Pp. 469. (Cambridge: At the University Press, 1961.) 120s.; 20 dollars.

\footnotetext{
$7 \mathrm{HE}$ annual volume of zoological literature is now so vast that tracing the history of even a single species, for systematic and distributional studies, is often a major task, especially in laboratories with poor library facilities. For this reason, carefully compiled synopses by acknowledged experts in their field are very valuable aids to research.

During the past fifty years Dr. Paul Kramp has made major contributions to our knowledge of medusæ of the cnidarian classes Hydrozoa and
}

Scyphozoa, and his comprehensive synopsis is an authoritative and much-needed volume. It covers the period 1910-60 and thus follows on from the very complete bibliographic Materiaux of Bedot and from Mayer's monographic Medusce of the World, both covering the earlier periods up to 1910. This new work deals with about 900 specigs, and Dr. Kramp has "followed the principle that it is better to retain too many species than to unite species whose identity cannot be stated with certainty, thereby causing confusion in zoogeographical discussions".

Orders, families and genera are briefly defined, and for the last-mentioned, important references to the generic concepts of different authors are also given. Similarly, succinct diagnoses of individual species are set out in telegraphic style, followed by locality records in the following manner: "Browne, 1910, p. 11 , pl. 4, figs. 6, 7: Margelopsis australis n. sp; McMurdo Sound, Antarctica".

There are neither illustrations nor keys, and some knowledge of medusæ, at least to family-level, is necessary before the volume can be appreciated as a most useful tool in identification. In a few genera, Aequorea, for example, and in an imperfectly known group like the Stauromedusae, Dr. Kramp has drawn his information from original diagnoses so that future workers can relate their findings to published descriptions.

There are remarkably fow imperfections in so large a work, but according to present-day rules of nomenclature the following generic names replace those (in parentheses) favoured by Dr. Kramp: Corymorpha (Steenstrupia), Halocordyle (Pennaria) and Hydractinia (Stylactis). There is some confusion in the use of the generic names Stomotoca and Amphinema, which are synonymous; here they are kept apart and as a result Stomotoca (sensu Kramp) does not contain the type species for which Agassiz created the genus.

These, however, are only minor blemishes in a very well-produced synopsis that is going to prove of immense value to marine zoologists concerned with Nature's drift bottles. There is a complete bibliography for the period and an index to genera and their species.

W. J. ReES

\section{AN INTRODUCTION TO VIRUSES}

\section{Viruses}

By Dr. Kenneth M. Smith. Pp. vii $+134+16$ plates. (Cambridge: At the University Press, 1962.) 21s. net; 3.75 dollars.

IN this book Dr. Kenneth Smith has collected together a number of his more recent articles on viruses. To these he has added much new material, expanding the whole into a general introductory account of our present knowledge of these agents. The book is aimed at the student and the inquiring layman, and no one who has read the author's earlier works will be surprised that it is both delightfully written and well suited to such an audience.

After a brief historical introduction and a description of some selected examples of virus diseases, there is an account of how viruses are studied. Strangely, this is restricted almost entirely to methods for the purification of viruses. It includes, however, a very brief section on the chemical nature of viruses, in which, incidentally, the nucleic acid content of vaccinia is given as 0.8 per cent ribonucleic acid instead 